\title{
Burden on caregivers of people with schizophrenia: comparison between Germany and Britain
}

\author{
C. ROICK, D. HEIDER, P. E. BEBBINGTON, M. C. ANGERMEYER, J.-M. AZORIN, \\ T. S. BRUGHA, R. KILIAN, S. JOHNSON, M. TOUMI and A. KORNFELD \\ on behalf of the EuroSC Research Group
}

\section{Background Burden on the relatives of patients with schizophrenia may be influenced not only by patient and caregiver characteristics, but also by differences in mental health service provision.}

\begin{abstract}
Aims To analyse whether family burden is affected by national differences in the provision of mental health services.
\end{abstract}

\begin{abstract}
Method Patients with schizophrenia and their key relatives were examined in Germany ( $n=333)$ and Britain $(n=170)$. Differences in family burden in both countries were analysed with regression models controlling for patient and caregiver characteristics.
\end{abstract}

Results Family burden was associated
with patients' symptoms, male gender,
unemployment and marital status, as well
as caregivers' coping abilities, patient
contact and being a patient's parent.
However, even when these attributes
were controlled for, British caregivers
reported more burden than German
caregivers.

Conclusions National differences in family burden may be related to different healthcare systems in Germany and Britain. Support for patients with schizophrenia may be shifted from the professional to the informal healthcare sector more in Britain than in Germany.

Declaration of interest Partial
funding from $\mathrm{H}$. Lundbeck A/S (see
Acknowledgements).
Acknowledgements).
The burden on relatives of people with schizophrenia may be influenced not only by patient and caregiver characteristics (Baronet, 1999; Loukissa, 1995), but also by national differences in mental healthcare service provision. However, the results of the two international studies so far available are ambiguous. Magliano et al (1998) found greater family burden in Italy, Greece and Portugal and a lesser burden in Germany and Britain; they supposed a divide between Mediterranean and northern European countries. Van Wijngaarden et al (2003) observed a greater burden in Italy and Britain compared with The Netherlands, Spain and Denmark; they proposed that differences in mental health provision might be important. We evaluate this assumption by comparing Germany and Britain, two northern European countries that differ appreciably in the provision of mental health services. We analyse for the first time data from several centres in each country. Data were gathered at five time points, reflecting the situation of relatives over a 2-year time period.

\section{METHOD}

\section{Sample}

For our analysis of family burden, we chose two northern European countries that differ appreciably in the style of mental health service provision: Germany and Britain. The current per capita expenditure on mental health in Germany is appreciably higher than in Britain (US \$289v. \$203) (Statistisches Bundesamt, 1998; World Health Organization, 2005). Germany has on average 7.5 psychiatric beds per 10000 population, whereas Britain has only 5.8 (World Health Organization, 2005). The differences in the provision of mental health services for people with severe mental illness have been demonstrated using the European Service Mapping Schedule (Becker et al, 2002; Angermeyer et al,
2004). A comparison between Leipzig and London is particularly revealing: in Leipzig there were 14.7 in-patient beds per 10000 inhabitants, in London only 6.3. In addition, the provision of services for day and structured activities in Leipzig was greater than in London (71.7 v. 42.6 users per 10000 inhabitants per working day). However, access to residential care (2.9 v. 4.4 places per 10000 inhabitants) and to outpatient and community care $(99.7 v$. 110.5 users per 10000 inhabitants per month) was somewhat less in Leipzig than in London. Overall, the number of unmet needs for care (covering the dimensions basic living conditions, healthcare, social contact, functioning and services) seems higher among people with schizophrenia in Britain. Patients in London reported on average 2.3 types of unmet needs, those in Leipzig only 1.0 (Kilian et al, 2001; McCrone et al, 2001). The overall satisfaction with mental health services is a proxy indicator of the quality of patients' treatment, and in patients with schizophrenia from Leipzig it was clearly higher (4.0) than in those from London (3.4) (Mory et al, 2001; Ruggeri et al, 2003). Finally, satisfaction with relatives' involvement in psychiatric care, which is particularly relevant to family burden, is distinctly lower in Britain than in Germany (London $2.9 v$. Leipzig 3.8) (Mory et al, 2001; Ruggeri et al, 2003).

Our analysis is based on the European Schizophrenia Cohort (EuroSC) study carried out between 1998 and 2002 and described elsewhere in more detail (Bebbington et al, 2005). In the present study we analyse EuroSC data from Germany $(n=618)$ and Britain $(n=302)$. In each of these countries, catchment areas were chosen that were socio-demographically distinct and had different styles of service delivery, in order that between them they should be reasonably representative of the country as a whole.

The study in Germany was based in four catchment areas: the city of Leipzig (490000 inhabitants) and the county of Altenburg (120000 inhabitants living in villages and medium-sized towns) in former East Germany, together with the district of Hemer (the cities of Hemer, Iserlohn and Werdohl; 160000 inhabitants) and the county of Heilbronn (500000 inhabitants living in villages and medium-sized towns) in former West Germany. In Britain two centres were chosen: Islington, a socially deprived inner-city area of London 
(176000 inhabitants), and the reasonably affluent semi-rural area of Leicestershire (330 000 inhabitants).

In each centre, we identified and assessed a cohort of patients aged 18-64 years with a diagnosis of schizophrenia (according to DSM-IV criteria; American Psychiatric Association, 1994) and in contact with secondary psychiatric services. Homeless people, patients in forensic facilities and patients hospitalised for the preceding 12 months were excluded. The psychiatrists treating the patients helped with recruitment. All patients provided informed consent for participation in the study, which was approved by local ethical committees in Germany and the UK.

All recruited patients were asked if we could contact their key relatives, who were defined as the patient's main informal contact person. In 417 cases (Germany $n=285$, Britain $n=132$ ), either the patient or the relative declined or could not participate in the study. Data about non-participants, which were recorded only in Leipzig, show that in $44 \%$ of these cases the patient had no key relative, $27 \%$ did not permit contact with their key relative, in $25 \%$ of cases relatives refused to take part in the study, and in 3\% of cases the relatives were unable to take part in the study owing to their own illness or extreme age. Thus, in Germany the response rate was $68 \%$ of eligible dyads and it was probably similar in the UK.

In 503 cases (Germany $n=333$, Britain $n=170$ ) patients allowed us to contact their key relatives and the relatives agreed to take part in the study. Patients and caregivers were examined five times at 6-month intervals. We collected data over a total period of 2 years.

\section{Instruments}

All relatives were asked to complete the Involvement Evaluation Questionnaire (IEQ; Van Wijngaarden et al, 2000; Bernert et al, 2001). This self-administered questionnaire covers a broad domain of caregiving consequences and refers to burden experienced within the past 4 weeks. The instrument contains 27 core variables scored on five-point Likert scales ('never' to 'always'). These variables are summarised in a total score, comprising four distinct sub-scales (Van Wijngaarden et al, 2000):

(a) 'Supervision' (six items), referring to the relatives' tasks of monitoring the patients' medicine intake, sleep and dangerous behaviour;

(b) 'Worrying' (six items), covering serious concerns about the patient's health, safety and future;

(c) 'Tension' (nine items), referring to a strained interpersonal atmosphere between patient and relative (this subscale contains one item also used in the sub-scale 'supervision' and one also used in the sub-scale 'worrying');

(d) 'Urging' (eight items), referring to activation and motivation of the patient, such as encouragement of the patient to undertake activities.

The questionnaire also includes sociodemographic variables, a question regarding the number of hours per week patients and their relatives spend in face-to-face or telephone contact, and an item asking the relatives how well they cope with the patient's mental problems. The response categories of the last item are scored on five-point Likert scales from 'not at all' to 'completely'.

The IEQ was originally developed in The Netherlands. The translation into German and English included an initial translation by professional translators, who were informed about the content of the IEQ; a back-translation into Dutch by a native speaker; a comparison of the backtranslation with the original version of IEQ, discussed by the translator and the researchers; and a discussion of the translated questionnaire in focus groups consisting of caregivers and researchers. With this procedure, which is described in more detail elsewhere (Van Wijngaarden et al, 2000; Bernert et al, 2001), the translated versions were revised step by step, until they covered domains of family burden in an acceptably similar manner to the original. The validation of the translated versions showed that the IEQ scales had substantial reliability in both countries (van Wijngaarden et al, 2000; Bernert et al, 2001).

Patients were examined in face-to-face interviews by psychiatrists and psychologists who were independent of patient care, and who had completed a thorough interviewer training. The diagnosis of schizophrenia was confirmed using the Schedules for Clinical Assessment in Neuropsychiatry (SCAN; Wing et al, 1990). Patients were included in the study if their present state or their psychiatric history justified the diagnosis of schizophrenia. The severity of illness was assessed by means of the Positive and Negative Syndrome Scale (PANSS; Kay et al, 1987, 1989) referring to symptoms experienced within the preceding week.

\section{Statistical analysis}

The analytical strategy to establish national differences in caregiver burden relied on controlling for the characteristics of relatives and patients that might provide an account of national differences at the individual level. Clearly, if doing this eliminated national differences, this would effectively refute the possibility of an account in terms of national styles of service provision. The analyses relied on chi-squared tests, $t$ tests, the Mann-Whitney $U$-test and the Kolmogorov-Smirnov test, as appropriate. Random-effect error component regression models for unbalanced panel data were computed, using robust variance estimators (Baltagi, 2001). The IEQ total score and the four IEQ sub-scores provided the dependent variables of the models. In addition to the 'country' variable, patient and caregiver characteristics known to predict family burden or differing significantly between the national samples were included in the models as independent variables in order to control their effects. Random-effect error component regression models provide estimations combined for effects of time-invariant differences between participants on the dependent variable and for effects of transitory changes of the independent variables over time. Calculations were carried out using the Statistical Package for the Social Sciences (SPSS) version 11 and Stata version 9.0 for Windows.

\section{RESULTS}

Table 1 shows the socio-demographic characteristics of the sample at baseline. The mean age of caregivers was 49 years; almost two-thirds of them were female, and a third were parents of the affected patients. Two-thirds of the relatives were living with the patient. On average, the relatives reported a considerable capacity for coping with the patient's behaviour (mean score 3.7, s.d.=1.1). The two national samples showed no significant difference with regard to the caregivers' gender, age and marital status, and the proportion who were parents of patients or who lived with them. However, the 
both countries the greatest caregiver burden resulted from worries about the patient, and the least from supervisory obligations. There was no significant difference between Germany and Britain in burden from supervision, worrying or tension, but caregivers from Britain had significantly higher scores on the 'urging' components of the IEQ $(P<0.001)$.

Table 2 shows the regression model with the IEQ total score as the dependent variable. Independently of national location, burden was associated with caregiver variables: being the patient's parent, spending more hours with the patient and having less capacity to cope with the patient's behaviour. Of the patients' characteristics, high PANSS positive and negative symptom scores were linked to an increase in caregivers' burden, along with male gender, current unemployment and being married. However, the model indicates that, after controlling for individual level variables, 'country' remains a significant predictor of caregiver burden $(P=0.027)$, caregivers from Britain being more burdened than those from Germany. The model explained $22 \%$ of the variance in caregivers' burden.

Table 3 shows predictors of the family burden sub-scales. Although the burden was higher in Britain for all sub-scales, it was only significantly so for the sub-scale 'urging' (that is, the encouragement of motivation and activity) $(P<0.001)$. In contrast, patient's positive symptom scores, as well as caregivers' ability to cope and the patient's marital status, predicted family burden in all four IEQ sub-scales. In each sub-scale, higher caregiver burden was found in relatives of married patients, in caregivers with lower coping abilities and in caregivers of patients with higher positive symptom scores. Higher negative symptom scores were also significantly associated with greater family burden reported in the sub-scales 'urging', 'worrying', and 'supervision' but not 'tension'. Caregivers in greater contact with the patients experienced more burden related to 'urging'. Additionally, the parents of patients had higher scores on the 'worrying' sub-scale. Relatives of male patients had greater burden in the domains 'urging', 'tension' and 'supervision'. In contrast, relatives of currently employed patients experienced less burden in the domains 'urging', 'supervision' and 'worrying'. The independent variables mentioned above explain $14-23 \%$ of the variance in the burden indicated by the IEQ sub-scales. 
Table 2 Regression model with Involvement Evaluation Questionnaire total score as dependent variable (number of groups 419 , average observations per group 2.4)

\begin{tabular}{lrrr}
\hline Independent variables & Coeff. & s.e. robust & $P$ \\
\hline Country (0 Britain, I Germany) & -3.412 & 1.545 & 0.027 \\
Caregivers' gender (0 male, I female) & 0.712 & 1.258 & 0.57 I \\
Caregivers' relationship with patient (0 not parent, I parent) & 3.154 & 1.269 & 0.013 \\
Caregivers' weekly hours spent with patient & 0.560 & 0.257 & 0.030 \\
Caregivers' ability to cope with patient's behaviour & -2.091 & 0.430 & $<0.001$ \\
Patients' PANSS score & & & \\
$\quad$ Positive symptoms & 0.583 & 0.112 & $<0.001$ \\
$\quad$ Negative symptoms & 0.254 & 0.074 & 0.001 \\
Patients' gender (0 male, I female) & -4.210 & 1.299 & 0.001 \\
Patients' working situation (0 not employed, I employed) & -4.971 & 1.408 & $<0.001$ \\
Patients' marital status (0 not married, I married) & 4.579 & 1.667 & 0.006 \\
Constant & 50.223 & 2.330 & $<0.001$ \\
$R^{2}$ overall & & &
\end{tabular}

Coeff., coefficient; PANSS, Positive and Negative Syndrome Scale.

\section{DISCUSSION}

The total burden reported by the caregivers in our sample corresponds well with results from other studies. Thus, Van Wijngaarden et al (2000) found a mean total IEQ score of 50.6 in their pooled sample from five European countries. As in our investigation, those authors showed that relatives of people with schizophrenia experience the highest burden from worries and the lowest burden in relation to the supervision of the patient.
Our investigation clearly showed that caregiver burden in Britain is greater than in Germany, despite less time in mutual contact, less psychopathology and a better employment situation in the patient sample. Because our analysis controlled for significant patient and caregiver characteristics, the national difference in family burden may in part be explained by differences in the mental healthcare system. One reason could be that Germany has considerably more psychiatric beds than Britain. In Britain the main focus of mental healthcare is thus more in the extramural domain. Even in times of acute illness, this would tend to increase contact between patient and relative, with a consequent increase in burden. The fact that it did not might indicate an active process of withdrawal, which was nevertheless ineffective. Van Wijngaarden et al (2003) in their study on family burden in five European countries indeed found that IEQ levels tended to be higher where the number of psychiatric beds per capita was lower.

Furthermore, opportunities for daytime structured activities (which include work and work-related activities as well as other structured activities and social contact) are better in Germany than in Britain (Becker et al, 2002; Angermeyer et al, 2004). This could also affect caregivers' burden. Thus, Stengard et al (2000) argue that a link exists between patients' use of rehabilitative services and the burden on their caregivers. However, the higher proportion of working patients in the British sample might indicate that vocational services are better in Britain than in Germany. Although the proportions of sheltered or voluntarily employed participants were similar in both samples (7.5\% in Germany, $4.7 \%$ in Britain), the proportion of paid or self-employed participants was higher in the British sample $(7.8 \%$ in Germany, $18.8 \%$ in Britain). Although this might be the result of more successful vocational services, the lower severity of illness in the British sample and the better labour market situation in Britain

Table 3 Regression models with Involvement Evaluation Questionnaire sub-scale scores as dependent variables

\begin{tabular}{|c|c|c|c|c|}
\hline Independent variables & $\begin{array}{l}\text { Urging } \\
\text { (coeff.) }\end{array}$ & $\begin{array}{l}\text { Tension } \\
\text { (coeff.) }\end{array}$ & $\begin{array}{l}\text { Supervision } \\
\text { (coeff.) }\end{array}$ & $\begin{array}{l}\text { Worrying } \\
\text { (coeff.) }\end{array}$ \\
\hline Country (0 Britain, I Germany) & $-2.629 * * *$ & -0.658 & -0.198 & -0.500 \\
\hline Caregivers' gender ( 0 male, I female) & 0.265 & 0.607 & 0.260 & 0.514 \\
\hline Caregivers' relationship with patient ( 0 not parent, I parent) & 0.461 & 0.341 & 0.277 & $2.459 * * *$ \\
\hline Caregivers' weekly hours spent with patient & $0.372^{* * *}$ & 0.129 & 0.106 & 0.071 \\
\hline Caregivers' ability to cope with patient's behaviour & $-0.436 *$ & $-0.917^{* * *}$ & $-0.308^{* *}$ & $-0.789 * * *$ \\
\hline \multicolumn{5}{|l|}{ Patients' PANSS score } \\
\hline Positive symptoms & $0.126 * *$ & $0.160 * * *$ & $0.095^{* * *}$ & $0.258^{* * *}$ \\
\hline Negative symptoms & $0.132 * * *$ & 0.033 & $0.033^{*}$ & $0.078 * *$ \\
\hline Patients' gender ( 0 male, I female) & $-1.629 * *$ & $-0.863 *$ & $-1.319 * * *$ & -0.561 \\
\hline Patients' working situation ( 0 not employed, I employed) & $-1.967^{* * *}$ & -0.534 & $-0.944^{* *}$ & $-1.859 * * *$ \\
\hline Patients' marital status ( 0 not married, I married) & $1.449 *$ & $\mathrm{I} .73 \mathrm{I}^{* *}$ & $0.835^{*}$ & $1.278^{*}$ \\
\hline Constant & $15.369 * * *$ & $15.459 * * *$ & $9.117 * * *$ & $13.850 * * *$ \\
\hline$R^{2}$ overall & 0.19 & 0.17 & 0.14 & 0.23 \\
\hline
\end{tabular}

Coeff., coefficient; PANSS, Positive and Negative Syndrome Scale.

$* P<0.05, * * P<0.01, * * * P<0.001$. 
probably had the greater influence - in 2005 the unemployment rate in Germany was $9.5 \%$ whereas in Britain it was only $4.7 \%$ (Statistical Office of the European Communities, 2006).

Although Germany provides more inpatient care $(233 \%$ of the capacity in Britain) and more day and structured activities ( $168 \%$ of the capacity in Britain), it has less residential care $(66 \%$ of the capacity in Britain) and less out-patient and community care $(90 \%$ of the capacity in Britain) (Angermeyer et al, 2004). Consequently, Britain has at least in some service areas a better mental healthcare system than Germany. This might counter the assumption that the observed differences in family burden are caused by differences in mental healthcare provision. However, the differences in residential and out-patient or community care are small compared with those in in-patient care and day and structured activities. Moreover, the better opportunities for out-patient and community care once again support the assertion that in Britain the main focus of mental healthcare is in the extramural domain, which might in practice be connected with increased family burden. In contrast, the better opportunities for residential care should in principle actually decrease family burden (Tessler \& Gamache, 1994); in our study, however, they probably did not have an important influence, because the utilisation of these services scarcely differed between the two samples (British sample $6.5 \%$, German sample $7.2 \% ; P=0.631$ ).

However, family burden might be influenced not only by the quantity of mental health service provision, but also by its accessibility and quality. There is some evidence relating to this. Thus, the higher number of unmet needs for care observed in patients from Britain with schizophrenia (Kilian et al, 2001; McCrone et al, 2001) might contribute to a greater burden on caregivers. Meijer et al (2004) reported such an association, especially for the IEQ domains 'worrying' and 'urging'. In our sample the greatest differences between relatives from Britain and Germany were also in the IEQ sub-scale 'urging'. This suggests that insufficient support for patients in Britain requires relatives to take over, entirely or partly, tasks that are covered by the mental healthcare system in Germany. Such tasks include urging patients to take proper care of themselves or to undertake some kind of activity, accompanying them to outside venues, and ensuring that they have taken the required medicine. If such tasks are undertaken by professional staff in day and structured activity services, the caregivers are consequently relieved of them.

In addition to national differences, our study confirmed patient and caregiver characteristics already known to be associated with family burden. Thus, reduced family burden was predicted by better caregiver coping abilities (Budd et al, 1998; Magliano et al, 1998; Baronet, 1999), and less severe positive and negative symptoms in the patient (Provencher \& Mueser, 1997; Schene et al, 1998; Wolthaus et al, 2002; Lowyck et al, 2004). This applied not only to the IEQ total score, but also to all four sub-scales of burden. Our results also confirm that caregivers in greater contact with the patient experience greater burden (Winefield \& Harvey, 1994; Schene et al, 1998; Warner, 2000). This was especially the case with regard to patient activation and motivation tasks (sub-scale 'urging'). Additionally, our study indicates that parents may be more burdened than other relatives, as was also found by Lowyck et al (2004). Not unexpectedly, caregiving parents seem especially prone to high levels of worry over their ill children.

Our results are also in line with those of Hoenig \& Hamilton (1966), who found that relatives of male patients reported more subjective and objective burden than those of female patients. Pickett et al (1995) showed that the burden experienced by family members, especially their worries, was less when the ill person was employed. Again, we found the same. To our knowledge no one has previously documented the high levels of burden experienced by the family members of married patients. This connection only applies to those who are married, not cohabiting. This may reflect the fact that, for the most part, these patients married before they fell ill. Their spouses may consequently sense a heavier burden on their life and on their future plans than partners who got to know the patient after the illness began.

\section{Limitations}

The aim of our investigation was to examine whether national differences between Germany and Britain in the burden experienced by the caregivers of people with schizophrenia could be explained solely in terms of individual attributes, or whether some of the differences might derive from attributes of the healthcare system. We did this by controlling for patient and caregiver characteristics known to predict family burden or differing significantly between the samples. However, although the level of social support received by relatives is a known predictor of care-related burden (Magliano et al, 1998), we had no information about this and therefore could not control for it.

Although our results reflect the situation in the catchment areas chosen, they may be generalisable to the situation in the countries as a whole, given that the catchment areas were chosen to be jointly representative (Bebbington et al, 2005). However, it has been taken into account that the German study population did not contain a sample from a major, multicultural city equivalent to London, with its inner-city catchment area of Islington. Therefore, the British sample might have included more individuals with multiple psychosocial problems, which may explain some of the variance observed in the study. Furthermore, we had no comparable data about the amount of caregiver service provision in Germany and Britain, although the amount of professional support to relatives may be related to the burden experienced (Warner, 2000).

Finally, we were unable to provide a true non-response rate among eligible dyads in Britain. Given the similarity of the non-participation rates, the British non-response rate was probably also similar to that in Germany, where it was an acceptable $68 \%$.

\section{Concluding remarks}

Differences in the caregiving burden reported by relatives of people with schizophrenia in Britain and Germany persisted even after we controlled for patient and caregiver characteristics. These differences may well be related to the different healthcare systems in the two countries. Our results suggest that, in comparison with Germany, the support of patients with schizophrenia falls more to the informal than the professional healthcare domains in Britain. This possibility should be analysed more closely in future studies, in particular whether the cost savings achieved at the expense of relatives ultimately result in health problems from the increased care-related burden. Family burden is of course only one aspect of mental healthcare. Patient outcomes are the other 
important aspect that must be more intensively addressed in future international health system comparisons.

\section{ACKNOWLEDGEMENTS}

The study was funded by $\mathrm{H}$. Lundbeck $\mathrm{A} / \mathrm{S}$ and by grants from the German Federal Ministry of Education and Research in the framework of the Research Association Public Health Saxony (grant 0IEG9732/7)

The EuroSC Research Group is composed of the following: Altenburg: I. Lindenbach, M. Swiridoff; Eppingen: F. Baehr, G. Lauer, T. Schwarz; Hemer: V. Becker, J. Höffler, K. Siegrist, U. Trenckmann; Leicester: T. Brugha, J. Smith, D. Bagchi, S. McCormack, S. Wheatley; Leipzig: M. Angermeyer, S. Bernert, R. Kilian, H. Matschinger, C. Mory, C. Roick; Lille: M. Goudemand, D. Beaune, S. Dumont; London: P. Bebbington, D. Ellis, L. Isham, S. Johnson, J. Pearson, E. Perez, A. Regan, R. White; Lyon: B. Lachaux, P. Pasi-Delay, S. Declerck; Marseille: J. M. Azorin, J. P. Chabannes, P. Chiaroni, I. Banovic; Lundbeck A/S M. Toumi, A. Kornfeld, K. Hansen, C. Morin, L. Munier, J.C. Nachef, C. Nickel, C. Sapin, V.Willacy

\section{REFERENCES}

American Psychiatric Association (1994) Diagnostic and Statistical Manual of Mental Disorders (4th edn) (DSM-IV). APA

Angermeyer, M. C., Roick, C., Becker, T., et al (2004) Cost-effectiveness of mental health service systems in the European comparison. In Public Health in Europe. 10 Years EUPHA. (ed W. Kirch), pp. 189-20I. Springer.

Baltagi, B. H. (200I) Econometric Analysis of Panel Data. Wiley.

Baronet, A. M. (1999) Factors associated with caregiver burden in mental illness: a critical review of the research literature. Clinical Psychology Review, 19, 819841 .

Bebbington, P. E., Angermeyer, M., Azorin, J. M., et al (2005) The European Schizophrenia Cohort (EuroSC): a naturalistic prognostic and economic study Social Psychiatry and Psychiatric Epidemiology, 40, 707717.

Becker, T., Huelsmann, S., Knudsen, H. C., et a (2002) Provision of services for people with schizophrenia in five European regions. Social Psychiatry and Psychiatric Epidemiology, 37, 465-474.

Bernert, S., Kilian, R., Matschinger, H., et al (200I) The assessment of burden on relatives of mentally ill people: the German version of the involvement evaluation questionnaire (IEQ-EU). Psychiatrische Praxis, 28 (suppl. 2), S97-I0I.

Budd, R. J., Oles, G. \& Hughes, I. C. (1998) The relationship between coping style and burden in the carers of relatives with schizophrenia. Acta Psychiatrica Scandinavica, 98, 304-309.

Hoenig, J. \& Hamilton, M.W. (1966) The schizophrenic patient in the community and his effect on the household. International Journal of Social Psychiatry I2, 165-176.

CHRISTIANE ROICK, MD, MPH, DIRK HEIDER, Department of Psychiatry, University of Leipzig, Germany; PAUL E. BEBBINGTON, MD, Department of Mental Health Sciences, University College, London, UK; MATTHIAS C. ANGERMEYER, MD, Department of Psychiatry, University of Leipzig, Germany; JEAN-MICHEL AZORIN, MD, Service Hospitalo-Universitaire de Psychiatrie, Marseille, France; TRAOLACH S. BRUGHA, MD, Department of Health Sciences, University of Leicester, UK; REINHOLD KILIAN, PhD, Department of Psychiatry II, University of Ulm, Günzburg, Germany; SONIA JOHNSON, MRCPsych, Department of Mental Health Sciences, Royal Free and University College Medical School, London, UK; MONDHER TOUMI, MD, ASA KORNFELD, Lundbeck SAS, Paris, France, on behalf of the EuroSC Research Group.

Correspondence: Dr. med. Christiane Roick, MPH, University of Leipzig, Department of Psychiatry, Johannisallee 20, 04317 Leipzig, Germany. Tel: +49 34I 972 45I2; fax: +49 341 972 4539; email: christiane.roick@medizin.uni-leipzig.de

(First received 26 April 2006, final revision 3 November 2006, accepted 14 November 2006)

Kay, S. R., Fiszbein, A. \& Opler, L. A. (1987) The Positive and Negative Syndrome Scale (PANSS) for schizophrenia. Schizophrenia Bulletin, 13, 26I-276.

\section{Ty, S. R., Opler, L. A. \& Lindenmayer, J. P. (1989)} The Positive and Negative Syndrome Scale (PANSS): rationale and standardisation. British Journal of Psychiatry, I55 (suppl. 7), s59-s67.

Kilian, R., Bernert, S., Matschinger, H., et al (200I) The standardized assessment of the need for treatment and support in severe mental illness: the development and testing of the German version of the Camberwell assessment of Need-EU. Psychiatrische Praxis, 28 (suppl. 2), S79-83.

Loukissa, D. A. (1995) Family burden in chronic mental illness: a review of research studies. Journal of Advanced Nursing, 2I, 248-255

Lowyck, B., De Hert, M., Peeters, E., et al (2004) A study of the family burden of 150 family members of schizophrenic patients. European Psychiatry, 19, 395-401.

Magliano, L., Fadden, G., Madianos, M., et al (1998) Burden on the families of patients with schizophrenia: results of the BIOMED I study. Social Psychiatry and Psychiatric Epidemiology, 33, 405-4I2.

McCrone, P., Leese, M., Thornicroft, G., et al (200I) A comparison of needs of patients with schizophrenia in five European countries: the EPSILON Study. Acto Psychiatrica Scandinavica, 103, 370-379.

Meijer, K., Schene, A., Koeter, M., et al (2004) Needs for care of patients with schizophrenia and the consequences for their informal caregivers - results from the EPSILON multicentre study on schizophrenia. Social Psychiatry and Psychiatric Epidemiology, 39, 25I258.

Mory, C., Matschinger, H., Roick, C., et al (200I) The German adaptation of the Verona Service Satisfaction Scale: an instrument for patients' satisfaction with mental health care. Psychiatrische Praxis, 28 (suppl. 2), S9I-96.

Pickett, S. A., Greenley, J. R. \& Greenberg, J. S. (1995) Off-timedness as a contributor to subjective burdens for parents of offspring with severe mental illness. Family Relations, 44, 195-20I.

Provencher, H. L. \& Mueser, K. T. (1997) Positive and negative symptom behaviors and caregiver burden in the relatives of persons with schizophrenia. Schizophrenia Research, 26, 7I-80.
Ruggeri, M., Lasalvia, A., Bisoffi, G., et al (2003) Satisfaction with mental health services among people with schizophrenia in five European sites: results from the EPSILON Study. Schizophrenia Bulletin, 29, 229-245.

Schene, A. H., van Wijngaarden, B. \& Koeter, M. W. (1998) Family caregiving in schizophrenia: domains and distress. Schizophrenia Bulletin, 24, 609-618.

Statistical Office of the European Communities (2006) Total Unemployment Rate. Statistical Office of the European Communities.

Statistisches Bundesamt (1998) Gesundheitsbericht für Deutschland. Metzler-Poeschel.

Stengard, E., Honkonen, T., Koivisto, A. M., et al (2000) Satisfaction of caregivers of patients with schizophrenia in Finland. Psychiatric Services, 5I, 1034 1039.

Tessler, R. \& Gamache, G. (1994) Continuity of care, residence, and family burden in Ohio. Milbank Quarterly, 72. 149-169.

Van Wijngaarden, B., Schene, A. H., Koeter, M., et al (2000) Caregiving in schizophrenia: development, internal consistency and reliability of the Involvement Evaluation Questionnaire - European Version: EPSILON Study 4. British Journal of Psychiatry, 177, s21-27.

Van Wijngaarden, B., Schene, A., Koeter, M., et o (2003) People with schizophrenia in five countries: conceptual similarities and intercultural differences in family caregiving. Schizophrenia Bulletin, 29, 573-586.

Warner, R. (2000) The Environment of Schizophrenia Innovations in Practice, Policy and Communications. Brunner-Routledge.

Winefield, H. R. \& Harvey, E. J. (1994) Needs of family caregivers in chronic schizophrenia. Schizophrenia Bulletin, 20, 557-566.

Wing, J. K., Babor, T., Brugha, T., et al (1990) SCAN Schedules for Clinical Assessment in Neuropsychiatry. Archives of General Psychiatry, 47, 589-593.

Wolthaus, J., Dingemans, P., Schene, A., et al (2002) Caregiver burden in recent-onset schizophrenia and spectrum disorders: the influence of symptoms and personality traits. Journal of Nervous and Mental Disease, 190, 241-247.

World Health Organization (2005) Mental Health Atlas-2005.World Health Organization. (http:// www. who. int/globalatlas/pgrms/mentalhealth/). 